\title{
Changing patients' profile presenting for surgical management of benign prostatic hyperplasia over the past 16 years: A single-centre perspective
}

\author{
Mohamed A. Elkoushy, MD, MSc, PhD; ${ }^{*}$ Ahmed M. Elshal, MD, FEBU, PhD, ${ }^{*}$ Mostafa M. Elhilali, MD, PhD, \\ FRCSC ${ }^{*}$
}

*Department of Surgery, Division of Urology, McGill University Health Centre, Montreal, QC; 'Department of Urology, Suez Canal University, Ismailia, Egypt; §Urology and Nephrology Center, Mansoura University, Mansoura, Egypt

See related article on page 379 .

Cite as: Can Urol Assoc J 2015;9(11-12):372-8. http://dx.doi.org/10.5489/cuaj.3066

Published online December 14, 2015.

\section{Abstract}

Introduction: We assessed the change of patients' profile presenting for symptomatic benign prostatic hyperplasia (BPH) over 16 years and its impact on surgical outcomes over this time.

Methods: We reviewed a prospectively maintained database of patients treated with laser for symptomatic BPH since March 1998. Patients were divided into 3 consecutive time-based groups: Group 1 for patients who underwent surgery before April 2004; Group 2, between April 2004 and March 2009; and for Group 3 from April 2009 to August 2014. We reviewed demographic and preoperative data, including prostate volume; international prostate symptoms score (IPSS), quality of life (QoL), and peak flow rate (Qmax). We also recorded any perioperative and long-term complications.

Results: A total of 1835 patients were included in our study, including $542(29.5 \%)$ in Group 1, 614 (33.5\%) in Group 2, and 679 $(37 \%)$ in Group 3. Preoperative prostate volume was positively correlated with age at surgery $(r=0.62, \mathrm{p}<0.001)$, total energy used $(r=0.47, p<0.001)$, and total operative time $(r=0.47, p<0.001)$. Patients in Group 3 were significantly older (75.28 \pm .47 in Group 3 vs. $71.11 \pm 8.9$ in Group 2 vs. $65.3 \pm 9.04$ years in Group 1, $p<0.001)$, were more coagulopathic (18.7\% Group 3 vs. $12.3 \%$ Group 2 vs. 5.9\% Group 1, $p<0.001)$, and had significantly larger prostates (87.96 \pm 49.80 in Group 3 vs. $78.44 \pm 50.84$ in Group 2 vs. $74.50 \pm 46.53$ Group $1, p<0.001)$. Preoperative prostatic medications significantly increased over time $(72.6 \%$ in Group 1 vs. 85.5\% in Group 2, vs. 87.4\% Group 3, p < 0.001). IPSS, QoL and Qmax were significantly abnormal in patients in Group $3(p<0.001)$. After a mean follow-up of 3 years, the number of patients who did not require reoperation progressively increased (94.1\% Group 1 vs. 96.1\% Group 2 vs. 98.3\% Group 3). Age (>72 years), prostate volume (>80 cc), operative time (>95 minutes), and preoperative PSA ( $>6 \mathrm{ng} / \mathrm{dL}$ ) were significantly associated with postoperative urinary incontinence.

Conclusions: Patients presenting for surgery due to symptomatic $\mathrm{BPH}$ over the last 16 years were significantly older, more morbid, and had larger prostates and more abnormal voiding parameters. Over time, patients used prostatic medications more frequently. Despite the changes in patient profiles, perioperative safety and complication rates between groups were comparable, likely due to advancements in laser technology and techniques. Age ( $>72$ years), prostate volume ( $>80 \mathrm{cc}$ ), operative time ( $>95$ minutes), and preoperative PSA ( $>6 \mathrm{ng} / \mathrm{dL}$ ) were significantly associated with reversible postoperative urinary incontinence.

\section{Introduction}

Since its development in the early 1990s, alpha-adrenergic blockers have been widely accepted as the first-line choice for lower urinary tract symptoms (LUTS) secondary to noncomplicated benign prostate hyperplasia (BPH). ${ }^{1}$ Short- and long-term randomized clinical trials have demonstrated the efficacy of these medications, either alone or in combination with 5-alpha reductase inhibitors.

Combination therapy significantly decreases clinical progression, acute urinary retention and $\mathrm{BPH}$-related surgery in men with moderate to severe LUTS; ${ }^{2-4}$ improves bladder outlet obstruction; and protects against impaired detrusor contractility. ${ }^{5}$ However, medical therapy has its own limitations and its failure results in worsening of symptoms and recurrent attacks of acute urinary retention and hydronephrosis which necessitate surgery. 6,7 About $8 \%$ of subjects receiving medical therapy required subsequent surgical therapy. ${ }^{8}$

Despite the $16 \%$ increase in the number of men at risk of BPH-related events, the advent of medical therapy for $\mathrm{BPH}$ has significantly delayed the time at which patients progress to BPH surgery. ${ }^{9}$ As such, it has decreased the number of transurethral resection of the prostate (TURPs) dramatically. ${ }^{7}$ In addition, significant comorbidities, including increased body mass index, hypertension and operative 
history, have increased in patients presenting with symptomatic BPH. ${ }^{10}$

Furthermore, as the population ages, more and more people will require medical care. ${ }^{11}$ Any delay in surgical therapy, when indicated, can cause progression of $\mathrm{BPH}$ and worsen its symptoms. Late presenting elderly patients coming for surgery have larger prostates with more cardiovascular diseases mandating long-term use of blood thinners, frequent use of cardiac pacemakers, and are often catheter dependent. ${ }^{11,12}$ Nevertheless, the surgical challenge associated with $\mathrm{BPH}$ treatment goes hand in hand with progressive evolution of techniques and refinement of the equipment.

The question is whether the evolution in surgical management techniques over the past 16 years has been able to maintain surgical outcomes despite significant changes in the target population. Furthermore, how does delay of surgery to relieve bladder outlet obstruction secondary to $\mathrm{BPH}$ affect recovery of the detrusor function?

We hypothesized that the widespread and prolonged medical treatment for symptomatic $\mathrm{BPH}$ delays surgical intervention, so that patients who eventually need surgery for $\mathrm{BPH}$ end up with more advanced disease. The intention of the present study was to assess the change in the profile of patients presenting for surgical management for LUTS secondary to BPH over the past 16 years and find out how much this change influenced their surgical outcomes.

\section{Methods}

\section{Study design and patients enrollment}

We reviewed a prospectively maintained laser prostate surgery database for patients presenting with symptomatic BPH since March 1998. Patients were divided into 3 consecutive time-based groups depending on their date of surgery: Group 1 for patients who were operated before April 2004; Group 2 for patients who were operated between April 2004 and March 2009; and Group 3 for patients who were operated thereafter until August 2014. All patients were evaluated, operated and supervised by a single surgeon (MME).

\section{Data collection and preoperative workup}

Demographic and preoperative data included age at surgery, presentation, presence of diabetes mellitus or coagulopathy, use of any prostatic medications for $\mathrm{BPH}$, and history of previous prostatic surgery. After patients' interview, we conducted physical and clinical examinations, including digital rectal examination (DRE), international prostate symptoms score (IPSS) and quality of Life (QoL) index, measurement of peak flow rate (Qmax), post-void residual urine by ultrasonography, prostate volume by transrectal ultrasound
(TRUS), and prostate-specific antigen (PSA). Patients with abnormal DREs and/or high PSA (greater than the average for their age) underwent TRUS-guided prostate biopsy before surgery, where only patients with negative biopsy underwent surgery.

The American Society of Anesthesiologists (ASA) morbidity scores at the time of surgery were recorded and used as a surrogate measure for overall patient comorbidity. Moreover, the date and type of surgery and concomitant procedures were reviewed. In addition, we documented postoperative complications, including the need for any further surgical intervention to relieve bothersome LUTS after the primary procedure.

Urinary incontinence was defined as the accidental or involuntary leakage of urine immediately preceded by urgency or straining. In our study, urinary incontinence included all types of incontinence (urgency, stress, or mixed).

\section{Outcome measures}

The primary outcome of the current study was to assess the change in the profile of patients presenting for surgical management for symptomatic BPH over the past 16 years. The secondary outcome was to compare the postoperative surgical outcome among the three consecutive study groups.

\section{Statistical analysis}

Descriptive statistics were reported in terms of number and percentages or means and standard deviations for categorical and continuous variables, respectively. The Fisher exact test was used for categorical variables, and one-way ANOVA or Kruskal-Wallis $\mathrm{H}$ test were used for normally and abnormally distributed continuous variables, respectively. Links between quantitative variables were measured by the Spearman rank correlation coefficient with a critical twosided $p$ value $<0.05$ used for statistically significant differences. A multivariate logistic regression model was used to assess predictors of postoperative urinary incontinence. Data were analyzed using the commercially available Statistical Package for Social Sciences for windows, version 20 (IBM SPSS, Armonk, NY).

\section{Results}

A total of 1835 patients underwent surgery between March 1998 and August 2014, including 542 (29.5\%), 614 (33.5\%), and 679 (37\%) patients in Group 1, Group 2, and Group 3 , respectively (Table 1 ). The overall prostate size was $80.5 \pm 49.5 \mathrm{~mL}$ and PSA was $5.97 \pm 11 \mathrm{ng} / \mathrm{mL}$. The overall mean (range) follow-up was 7.8 years ( 3 months- 15 years); $12.8 \pm 5.9$ years for Group 1, $8.2 \pm 4.7$ years for Group 2, and $3.1 \pm 9.3$ years for Group 3 . 


\begin{tabular}{lc}
\hline \multicolumn{2}{l}{ Table 1. Demographic and overall preoperative voiding } \\
parameters & $\begin{array}{c}\text { Mean } \pm \text { SD / } \\
\text { No. (\%) }\end{array}$ \\
\hline Parameter & $72.0 \pm 8.8$ \\
& $117(6.4 \%)$ \\
\hline Age at surgery (years) & $1496(81.5 \%)$ \\
Patients with DM & $590(32.2 \%)$ \\
Medications for LUTS & $1.4 \pm 0.67$ \\
Patients presented with indwelling urethral & $18.7 \pm 7.7$ \\
catheters & $3.7 \pm 1.5$ \\
ASA score & $6.9 \pm 5.1$ \\
IPSS & $255 \pm 342$ \\
Quality of life score & $5.97 \pm 11$ \\
Peak flow rate (mL/sec) & $80.5 \pm 49.5$ \\
Post-void residual urine volume /mL & $126.4 \pm 41.4$ \\
PSA (ng/dL) & $129(7.0)$ \\
Preoperative prostate size by TRUS (cc) & \\
Preoperative hemoglobin (g/dL) & $1277(69.6)$ \\
Concomitant cystolitholapaxy & $67(3.7)$ \\
Type of surgery & $406(22.1)$ \\
Holmium laser enucleation & $85(4.6)$ \\
\hline Holmium laser ablation & \\
Green light laser procedures & \\
Holmium transurethral incision of the prostate & \\
\hline DM: diabetes mellitus; LUTS: lower urinary tract symptoms; ASA: American Society of \\
Anesthesiologists; IPS: International Prostate Symptoms Score; PSA: prostate-specific \\
antigen; TRUS: transurethral ultrasound.
\end{tabular}

All patients underwent laser prostate surgery, including holmium laser enucleation (HoLEP) in 1277 (69.6\%),
Holmium laser ablation (HOLAP) in $67(3.7 \%)$, GreenLight photoselective vaporization procedures (PVP) in 406 (22.1\%) and holmium transurethral incision of the prostate (Ho-TUIP) in $85(4.6 \%)$ patients. Preoperative prostate volume was positively correlated with age at surgery $(r=0.62, p<0.001)$, total energy used $(r=0.47, p<0.001)$, and total operative time $(r=0.47, p<0.001)$.

Patients in Group 3 were significantly older, for Group 3, Group 2 and Group 1, respectively (75.28 \pm 8.47 vs. $71.11 \pm 8.9$ vs. $65.3 \pm 9.04$ years, $p<0.001)$, were more coagulopathic $(18.7 \%$ vs. $12.3 \%$ vs. $5.9 \%, p<0.001)$, and had significantly more morbidity (higher mean ASA score) (Table 2). The use of preoperative prostatic medications significantly increased over time $(72.6 \%$ vs. $85.5 \%$, vs. $87.4 \%$, $p<0.001$ ) in Group 1, Group 2 and Group 3, respectively (Table 2).

At the time of surgery, a significantly higher number of patients in Groups 3 and 2 had indwelling urethral catheters secondary to urinary retention $33.7 \%$ Group 3 vs. $34.4 \%$ Group 2 vs. 27.7 Group 1, $p=0.028$ ). Moreover, patients in Group 3 had significantly larger prostate volume compared to patients in Group 1 and Group 2, respectively $(87.96 \pm 49.80$ vs. $74.50 \pm 46.53$ vs. $78.44 \pm 50.84$, $p<0.001)$. Similarly, patients in Group 3 had significantly higher IPSS and QoL scores and lower Qmax than the other groups $(p<0.001)$ (Table 2$)$.

We tallied perioperative parameters and types of laser prostatectomy among the three groups (Table 3). Enucleation-

Table 2. Demographic and baseline voiding parameters among groups

\begin{tabular}{|c|c|c|c|c|c|}
\hline \multicolumn{2}{|l|}{ Variables } & $\begin{array}{l}\text { Group I } \\
n=542\end{array}$ & $\begin{array}{c}\text { Group II } \\
n=614\end{array}$ & $\begin{array}{c}\text { Group III } \\
n=679\end{array}$ & $p$ value \\
\hline \multicolumn{2}{|l|}{ Age at time of surgery (years) } & $65.3 \pm 9.04$ & $71.11 \pm 8.9$ & $75.28 \pm 8.47$ & $<0.001$ \\
\hline \multicolumn{2}{|l|}{ ASA scores } & $1.33 \pm 0.61$ & $1.21 \pm 0.51$ & $1.62 \pm 0.78$ & $<0.001$ \\
\hline \multicolumn{2}{|l|}{ Patients with DM } & $37(7.1)$ & $28(4.6)$ & $52(7.7)$ & 0.06 \\
\hline \multicolumn{2}{|l|}{ Coagulopathic patients } & $32(5.9)$ & $76(12.3)$ & $127(18.7)$ & $<0.001$ \\
\hline \multicolumn{2}{|c|}{ Patients presented with indwelling urethral catheters } & $150(27.7)$ & $211(34.4)$ & $229(33.7)$ & 0.028 \\
\hline \multicolumn{2}{|c|}{ Duration of dwelling catheter prior to surgery (weeks) } & $12.84 \pm 8.13$ & $11.98 \pm 7.82$ & $14.36 \pm 8.39$ & 0.026 \\
\hline \multicolumn{2}{|c|}{ Previous prostate surgery } & 52 (9.59) & $44(7.17)$ & $41(6.03)$ & 0.06 \\
\hline \multirow{4}{*}{$\begin{array}{l}\text { Preoperative prostate medications, } \\
\text { no }(\%)\end{array}$} & None & $148(27.3)$ & $108(17.6)$ & $86(12.7)$ & \multirow{4}{*}{$<0.00$} \\
\hline & Alpha blockers & $320(59.0)$ & $354(57.7)$ & $299(44.0)$ & \\
\hline & 5 ARls \pm alpha blockers & $74(13.7)$ & $152(24.7)$ & $294(43.3)$ & \\
\hline & Overall medications & $394(72.7)$ & $506(82.4)$ & $593(87.3)$ & \\
\hline \multicolumn{2}{|c|}{ Preoperative PSA (mean $\pm \mathrm{SD}, \mathrm{ng} / \mathrm{dL}$ ) } & $6.13 \pm 10.28$ & $5.85 \pm 10.69$ & $5.93 \pm 12.32$ & 0.92 \\
\hline \multicolumn{2}{|c|}{ Preoperative prostate size by TRUS (Mean \pm SD, cc) } & $74.50 \pm 46.53$ & $78.44 \pm 50.84$ & $87.96 \pm 49.80$ & $<0.001$ \\
\hline \multicolumn{2}{|c|}{ Preoperative $\operatorname{Qmax}(\mathrm{mL} / \mathrm{sec})$} & $8.12 \pm 6.95$ & $7.19 \pm 3.9$ & $6.02 \pm 4.4$ & $<0.001$ \\
\hline \multicolumn{2}{|l|}{ Preoperative PVR $(\mathrm{mL})$} & $238 \pm 216$ & $256 \pm 253$ & $278 \pm 263$ & 0.27 \\
\hline \multicolumn{2}{|l|}{ Preoperative IPSS } & $16.73 \pm 7.44$ & $19.60 \pm 7.49$ & $21.07 \pm 7.68$ & $<0.001$ \\
\hline \multicolumn{2}{|l|}{ Preoperative QoL } & $3.36 \pm 1.46$ & $3.74 \pm 1.49$ & $4.52 \pm 1.48$ & $<0.001$ \\
\hline \multicolumn{2}{|l|}{ Preoperative hemoglobin (g/dL) } & $135.74 \pm 25.78$ & $132.44 \pm 35.85$ & $104.74 \pm 56.21$ & $<0.001$ \\
\hline
\end{tabular}




\begin{tabular}{|c|c|c|c|c|c|}
\hline \multicolumn{2}{|l|}{ Variables } & $\begin{array}{c}\text { Group I } \\
\mathrm{n}=542(\%)\end{array}$ & $\begin{array}{c}\text { Group II } \\
\mathrm{n}=614(\%)\end{array}$ & $\begin{array}{c}\text { Group III } \\
\mathrm{n}=679(\%)\end{array}$ & $p$ value \\
\hline \multicolumn{2}{|l|}{ Operative time (min) } & $98.2 \pm 51.3$ & $87.7 \pm 46.9$ & $103.3 \pm 65.2$ & $<0.001$ \\
\hline \multicolumn{2}{|l|}{ Energy utilized (KJ) } & $188.3 \pm 142.4$ & $174.5 \pm 85.5$ & $197.9 \pm 123.9$ & $<0.001$ \\
\hline \multicolumn{2}{|c|}{ Length of hospital stay (days) } & $1.47 \pm 2.12$ & $1.06 \pm 0.77$ & $1.01 \pm 0.60$ & $<0.001$ \\
\hline \multicolumn{2}{|c|}{ Postoperative catheter duration (days) } & $1.34 \pm 1.68$ & $1.51 \pm 1.93$ & $1.40 \pm 2.12$ & 0.31 \\
\hline & Enucleation-based procedures* & $468(33.5)$ & $388(27.8)$ & $537(38.7)$ & $<0.001$ \\
\hline & HoLEP & $468(86.3)$ & $388(63.2)$ & $421(62.2)$ & $<0.001$ \\
\hline \multirow[t]{3}{*}{ Type of laser procedure } & HOLAP & $4(0.7)$ & $62(10.1)$ & $1(0.1)$ & $<0.001$ \\
\hline & Greenlight laser procedures & $5(0.9)$ & $153(24.9)$ & $248(36.5)$ & $<0.001$ \\
\hline & Ho-TUIP & $65(12)$ & $11(1.8)$ & $9(1.3)$ & $<0.001$ \\
\hline \multicolumn{2}{|c|}{ Concomitant cystolitholapaxy } & $34(6.3)$ & $43(7.0)$ & $52(7.7)$ & 0.64 \\
\hline
\end{tabular}

based procedures were significantly different among the 3 groups (33.5\% Group 1 vs. $27.8 \%$ Group 2 vs. $38.7 \%$ Group $3, p<0.001$ ) (Table 3).

We also tallied perioperative and late postoperative complications among groups (Table 4). After a mean follow-up of 3 years for all groups, reoperation-free patients progressively increased over time: $94.1 \%$ vs. $96.1 \%$ vs. $98.3 \%$ for Group 1, Group 2, and Group 3, respectively. Late development of prostate cancer was detected in $35(1.9 \%)$ patients who were primarily confirmed to have histological BPH. Late prostate cancer diagnosis was comparable among groups
(0.60\% Group 1 vs. $0.54 \%$ Group 2 vs. $0.76 \%$ Group 3, $p=0.13)$, respectively.

Of interest, failure of postoperative voiding trials and the development of early postoperative urinary incontinence were significantly lower in Group 1 (Table 4), despite the fact that surgeons had inherent learning curves with their techniques. Using the means of the whole cohort as cut-offs in a multivariate logistic regression model, age ( $>72$ years), prostate volume ( $>80 \mathrm{cc}$ ), operative time ( $>95$ minutes), and preoperative PSA ( $>6 \mathrm{ng} / \mathrm{dL}$ ) were significantly associated with postoperative urinary incontinence. All patients

Table 4. Perioperative and late postoperative complications among groups

\begin{tabular}{|c|c|c|c|c|c|c|}
\hline $\begin{array}{l}\text { Time of } \\
\text { complications }\end{array}$ & $\begin{array}{c}\text { Clavien- } \\
\text { Dindo Grade }\end{array}$ & Type of complication & $\begin{array}{c}\text { Group I } \\
\mathrm{n}=542 \text { No (\%) }\end{array}$ & $\begin{array}{c}\text { Group II } \\
\mathrm{n}=\mathbf{6 1 4} \text { No (\%) }\end{array}$ & $\begin{array}{c}\text { Group III } \\
\mathrm{n}=679 \text { No (\%) }\end{array}$ & $p$ value \\
\hline \multirow{4}{*}{$\begin{array}{l}\text { Operative } \\
\text { complications }\end{array}$} & \multirow{4}{*}{ Grade I } & Prostate capsule violation & $1(0.18)$ & $0(0)$ & $3(0.44)$ & 0.23 \\
\hline & & Bladder/urethral injury & $3(0.55)$ & $10(1.63)$ & $8(1.18)$ & 0.22 \\
\hline & & Bleeding & $11(2.03)$ & $23(3.74)$ & $27(3.98)$ & 0.13 \\
\hline & & Anaesthesia-related & $4(0.74)$ & $1(0.16)$ & $0(0)$ & 0.04 \\
\hline \multirow{6}{*}{$\begin{array}{l}\text { Early postoperative } \\
\text { complications } \\
\text { (within } 30 \text { days } \\
\text { postoperatively) }\end{array}$} & \multirow{3}{*}{ Grade I } & Postoperative hematuria & $7(1.29)$ & $13(2.12)$ & $13(1.91)$ & 0.07 \\
\hline & & Urinary incontinence & $15(2.77)$ & $40(6.51)$ & $25(3.68)$ & 0.004 \\
\hline & & Failed first TOV & $4(0.74)$ & $20(3.26)$ & $19(2.80)$ & 0.01 \\
\hline & \multirow{3}{*}{ Grade II } & Thromboembolic & $1(0.18)$ & $4(0.65)$ & $1(0.15)$ & 0.22 \\
\hline & & Epididymo-orchitis & $1(0.18)$ & $1(0.16)$ & $2(0.29)$ & 0.86 \\
\hline & & Need for transfusion & $11(2.13)$ & $2(0.32)$ & $2(0.29)$ & $<0.001$ \\
\hline \multirow{3}{*}{ Late Complications } & \multirow{2}{*}{ Grade I } & Persistent LUTS & $13(2.44)$ & $20(3.94)$ & $13(2.22)$ & 0.18 \\
\hline & & Hematuria (conservative) & $3(0.56)$ & $2(0.39)$ & $1(0.17)$ & 0.55 \\
\hline & \multirow{4}{*}{ Grade II } & Acute retention needs urethral catheter & $2(0.37)$ & $5(0.99)$ & $1(0.17)$ & 0.13 \\
\hline \multirow[t]{2}{*}{$\mathrm{n}=1626$} & & Chronic retention $(\mathrm{CIC})$ & $2(0.37)$ & $6(1.18)$ & $2(0.34)$ & 0.14 \\
\hline & & Recurrent UTI & $7(1.31)$ & $7(1.38)$ & $2(0.34)$ & 0.14 \\
\hline $\mathrm{G} \|=507$ & & Persistent incontinence $>12$ months & $5(0.99)$ & $8(1.58)$ & $3(0.51)$ & 0.20 \\
\hline \multirow[t]{3}{*}{$\mathrm{GIII}=586$} & & Bladder neck contracture & $13(2.44)$ & $12(2.37)$ & $5(0.85)$ & 0.08 \\
\hline & Grade IIIb & Urethral stricture & $19(3.56)$ & $15(2.96)$ & $2(0.34)$ & $<0.001$ \\
\hline & & Bladder stones & $5(0.99)$ & $3(0.59)$ & $3(0.51)$ & 0.62 \\
\hline
\end{tabular}

TOV: trial of void; LUTS: lower urinary tract symptoms; CIC: clean intermittent catheterization; UTI: urinary tract infection. 
who needed transfusion underwent a HoLEP procedure and despite the fact that consecutive time groups used blood thinners more frequently, the need for perioperative blood transfusion was significantly higher in Group 1 (Table 4).

\section{Discussion}

$\mathrm{BPH}$ is one of the most common conditions associated with aging men and up to $25 \%$ of men in their eighth decade of life require treatment. ${ }^{13}$ Bothersome symptoms are the most common reasons why men with $\mathrm{BPH}$ seek treatment. Therefore, therapeutic decision-making should be guided by the degree of bothersome symptoms and patient preference.

During the past decade, the introduction of highly effective combination drug therapies for BPH significantly delayed the time at which patients switched over to surgery. ${ }^{9}$ Furthermore, the progressive increase of life expectancy in the general population, particularly in western countries, resulted in more and more elderly people requiring medical care. ${ }^{11}$

Patients with acute urinary retention tend to require a longer hospital stay, incur higher costs, and experience a higher risk of complications after TURP than those without retention. ${ }^{14}$ Therefore, delay of surgical therapy, when indicated, can cause progression of $\mathrm{BPH}$ and worsen its outcome. In addition, significant comorbidities including increased body mass index, chronic medical diseases and operative history have increased in the last two decades for patients with symptomatic $\mathrm{BPH} .{ }^{10}$

In the current study, we compared 3 consecutive timebased groups of BPH patients surgically treated with different modalities of Holmium and GreenLight lasers, including ablation, incision and enucleation procedures. We found that preoperative prostate volume significantly correlated with age at surgery, total energy used at surgery, and the total operative time. It would seem intuitive as patients get older for surgery, their prostates get larger and they may need higher energy for their laser surgeries and longer operative time. Moreover, we found that patient and prostate characteristics were significantly different among the 3 groups. Group 3 was different; patients had significantly larger prostates, were older, had a higher comorbidity score, failed medical therapy, and required surgery. However, despite the fact that predictors of complications under these circumstances following transurethral prostate procedures were different, the procedure-related complications in our study were comparable among study groups.

Reports have shown that longer operative time, ${ }^{11}$ age, prostate size,$^{15}$ non-Caucasians, ${ }^{12}$ and perioperative blood thinners use $\mathrm{e}^{16}$ independently predict surgical morbidity and mortality for patients with BPH. In addition, post-TURP morbidity was significantly higher in patients over 80 and in patients with prostates larger than 45 cc. $^{17}$
In the current study, a higher proportion of patients in Group 3 were on preoperative combination drug therapy. Combination therapy has been shown to significantly improve LUTS more than monotherapy at 4 years and was superior to alpha-blocker-monotherapy in reducing the risk of acute urine retention or $\mathrm{BPH}$-related surgery and risk of $\mathrm{BPH}$ clinical progression..$^{4,18}$ In our socialized medical environment, patients with BPH have to wait longer for surgery, which could contribute to longer medical therapy. Furthermore, a poorer preoperative flow rate was observed in patients in Group 3; there were more catheter-dependent patients for surgery in the Groups 2 and 3, compared to Group 1. This could be explained by the long-term outflow obstruction in older patients with larger prostates, which would impair bladder detrusor contractility especially when the response to treatment is unsatisfactory. Saito and colleagues previously found that the total bladder pressure observed with experimental long-standing outflow obstruction was significantly lower than in their control group. ${ }^{19}$ Interestingly, there was no difference between the 3 time-groups in our study regarding the postoperative need of chronic clean intermittent catheterization - consistent with a report by Kojima and colleagues on the reversibility of detrusor muscle changes after relief of outflow obstruction. ${ }^{20}$

Longer medical treatment for $\mathrm{BPH}$ has been associated with a decreased number of patients undergoing BPH surgery resulting in increased prostate volume with potentially more patients needing open surgery. ${ }^{21}$ The question is whether changes in laser surgery over the past 16 years have been able to sustain surgical outcome despite significant changes in the target population. Fortunately, the currently available new laser technology and equipment confer benefits to these patients and could overcome the challenge of increased prostate volume and patient comorbidities. ${ }^{22}$ However, many clinical trials have shown higher reoperation rates after laser ablation of the prostate, ${ }^{23,24}$ despite the fact that many of these laser techniques claim to be size independent. ${ }^{25}$

Short- and long-term functional outcomes of these different procedures have been previously published, including 3 randomized controlled trials comparing the 3 generations of the 532-nm laser with holmium laser ablation and enucleation. $^{26-32}$

In our current study, all 3 successive groups were comparable regarding long-term adverse events and reoperation rates. However, there was a progressive decrease in the incidence of urethral stricture over time. This might be due to the lower incidence of previous prostate surgery in patients in Group 3 and the continuous refinement of instruments and quality of laser fibres over time. In addition, most patients in Group 3 underwent HoLEP, in which a new enucleation loop was used to help blunt the dissection of the adenoma, which could be a contributing factor. 
Of interest, failed postoperative trial of voiding was significantly lower in Group 1, which could be the result of significantly higher enucleation procedures in Group 1 patients and/or the significantly increased prostate volume in the other 2 groups. Surprisingly, early postoperative transient de novo urinary incontinence was significantly lower in Group 1 patients despite the steep learning curve during that time. However, this finding was not surprising considering our multivariate analysis where postoperative urinary incontinence was likely in patients over 72 , with prostates larger than $80 \mathrm{cc}$, a PSA over $6 \mathrm{ng} / \mathrm{dL}$, and with operation times over 95 minutes. These parameters may explain the significantly lower incidence of early urinary incontinence in Group 1 - with younger patients and smaller prostate volumes. In a previous study, the presence of diabetes mellitus, large prostate volume $(>81 \mathrm{cc})$ and a greater reduction in postoperative PSA ( $>84 \%$ ) predicted stress urinary incontinence after HoLEP. ${ }^{33}$ These factors suggest a relationship between the novel urinary incontinence and the length of the procedure.

Finally, our data are consistent with the current growing trend in the urologic community - more $\mathrm{BPH}$ patients presenting late for surgery with larger glands and adopting more transurethral enucleation techniques. Good-quality data support the use of enucleation techniques on larger glands to minimize reoperation rates; regardless of the type of energy source used, transurethral enucleation or vapoenucleation is increasing. ${ }^{34}$

Our study has its limitations, including the duration of preoperative prostatic medications that were not recorded in our database. Another limitation is the study's retrospective nature. In addition, a selection bias could have been introduced with the patients referred to our tertiary centre - patients were older, had larger prostates and had an increase in comorbidity. Moreover, all patients were managed by a new laser technology, which may have reduced the impact of patient profile changes on surgical outcomes. Nevertheless, our study conclusions are validated in that it included a large series of patients over a considerable long follow-up.

\section{Conclusion}

We have found that over a 16-year period, patients presenting for surgery due to symptomatic BPH were older, more morbid, and had larger prostates and more abnormal voiding parameters. Also, over time, we found more and more patients using prostatic medications more frequently. Despite changes in patient profiles, perioperative safety and complications rates were comparable between groups. This may be a results of advances in laser technology and techniques. Age $(>72$ years), prostate volume $(>80 \mathrm{cc})$, operative time ( $>95$ minutes), and preoperative PSA $(>6 \mathrm{ng} / \mathrm{dL}$ ) were significantly associated with reversible postoperative urinary incontinence.

Competing interests: Dr. Mostafa Elhilali is a consultant for AMS, Pfizer, Astellas and Boston Scientific.

This paper has been peer-reviewed.

\section{References}

1. Lepor $\mathrm{H}$, Auerbach S, Puras-Baez A, et al. A randomized, placebo-controlled multicentre study of the efficacy and safety of terazosin in the treatment of benign prostatic hyperplasia. J Urol 1992;148:1467-74.

2. Roehrborn (G, Siami P, Barkin J, et al. The effects of combination therapy with dutasteride and tamsulosin on clinical outcomes in men with symptomatic benign prostatic hyperplasia: 4-year results from the CombAT study. Eur Urol 2010;57:123-31. http://dx.doi.org/10.1016/i.eururo.2009.09.035

3. Bautista OM, Kusek JW, Nyberg LM, et al. Study design of the Medical Therapy of Prostatic Symptoms (MTOPS) trial. Control Clin Trials 2003;24:224-43. http://dx.doi.org/10.1016/S01972456(02)00263-5

4. McConnell JD, Roehrborn CG, Bautista OM, et al. The long-term effect of doxazosin, finasteride, and combination therapy on the clinical progression of benign prostatic hyperplasia. N Engl J Med 2003;349:2387-98. http://dx.doi.org/10.1056/NEJMoa030656

5. Boyle P, Roehrborn C, Harkaway R, et al. 5-Alpha reductase inhibition provides superior benefits to alpha blockade by preventing AUR and BPH-related surgery. Eur Urol 2004;45:620-6; discussion 626-7. http://dx.doi.org/10.1016/i.eururo.2003.09.012

6. Souvereina PC, Erkensb JA, de la Rosette JJ, et al. Drug treatment of benign prostatic hyperplasia and hospital admission for BPH-related surgery. Eur Urol 2003;43:528-34. http://dx.doi.org/10.1016/ S0302-2838(03)00089-7

7. Borth CS, Beiko DT, Nickel JN. Impact of medical therapy on transurethral resection of the prostate: A decade of change. Urology 2001;57:1082-5. http://dx.doi.org/10.1016/S0090-4295(01)01018-4

8. Saigal CS, Movassghi M, Pace J, et al. Economic evaluation of treatment strategies for benign prostatic hyperplasia-is medical therapy more costly in the long run? J Urol 2007;177:1463-7. http://dx.doi. org/10.1016/i.juro.2006.11.083

9. Roehrborn CG, Barkin J, Tubaro A, et al. Influence of baseline variables on changes in International Prostate Symptom Score after combined therapy with dutasteride plus tamsulosin or either monotherapy in patients with benign prostatic hyperplasia and lower urinary tract symptoms: 4 -year results of the CombAT study. BJU Int 2014;113:623-5. http://dx.doi.org/10.1111/bju.12500

10. Choi SY, Kim TH, Myung SC, et al. Impact of changing trends in medical therapy on surgery for benign prostatic hyperplasia over two decades. Korean J Urol 2012;53:23-8. http://dx.doi.org/10.4111/ kju.2012.53.1.23

11. Elshal AM, Elmansy HM, Elhilali MM. Transurethral laser surgery for benign prostate hyperplasia in octogenarians: Safety and outcomes. Urology 2013;81:634-9. http://dx.doi.org/10.1016/j.urology.2012.11.042

12. Bhojani N, Gandaglia G, Sood A, et al. Morbidity and mortality after benign prostatic hyperplasia surgery: Data from the American College of Surgeons national surgical quality improvement program. J Endourol 2014;28:831-40. http://dx.doi.org/10.1089/end.2013.0805

13. Jacobsen SJ, Jacobson DJ, Girman CJ, et al. Treatment for benign prostatic hyperplasia among community dwelling men: The Olmsted County study of urinary symptoms and health status. J Urol 1999;162:1301-6. http://dx.doi.org/10.1016/S0022-5347(05)68271-7

14. Chen JS, Chang $\mathrm{CH}$, Yang WH, et al. Acute urinary retention increases the risk of complications after transurethral resection of the prostate: A population-based study. BJU Int 2012;110:E896-901. http:// dx.doi.org/10.1111/i.1464-410X.2012.11471.x

15. Rausch S, Heider T, Bedke J, et al. Analysis of early morbidity and functional outcome of thulium: yttrium-aluminum-garnet laser enucleation for benign prostate enlargement: Patient age and prostate size determine adverse surgical outcome. Urology 2015;85:182. http://dx.doi.org/10.1016/i.urology.2014.10.002

16. Reich 0 , Gratzke C, Bachmann A, et al. Morbidity, mortality and early outcome of transurethral resection of the prostate: A prospective multicenter evaluation of 10,654 patients. J Urol 2008; 180:246-9. httrp:// dx.doi.org/10.1016/i.juro.2008.03.058 
Elkoushy et al.

17. Mebust WK, Holtgrewe HL, Cockett AT, et al. Transurethral prostatectomy: Immediate and postoperative complications. A cooperative study of 13 participating institutions evaluating 3,885 patients. J Urol 1989;141:243-7.

18. Roehrborn CG, Siami P, Barkin J, et al. The effects of combination therapy with dutasteride and tamsulosin on clinical outcomes in men with symptomatic benign prostatic hyperplasia: 4 -year results from the CombAT study. Eur Urol 2010;57:123-31. http://dx.doi.org/10.1016/i.eururo.2009.09.035

19. Saito $M$, Ohmura $M$, Kondo A. Restoration of rat bladder function following release of short- and longterm partial oufflow obstruction. Urol Res 1997;25:193-7. http://dx.doi.org/10.1007/BF00941982

20. Koijma $M$, Inui $E$, Ochiai $A$, et al. Reversible change of bladder hypertrophy due to benign prostatic hyperplasia after surgical relief of obstruction. J Urol 1997;158:89-93. http://dx.doi.org/10.1097/00005392199707000-00024

21. Vela- Navarrete R, Gonzalez-Enguita C, Garcia-Cardoso JV, et al. The impact of medical therapy on surgery for benign prostatic hyperplasia: A study comparing changes in a decade (1992-2002). BJU Int 2005;96:1045-8. http://dx.doi.org/10.1111/.1.1464-410X.2005.05735.x

22. Shin YS, Park JK. Changes in surgical strategy for patients with benign prostatic hyperplasia: 12-year single-center experience. Korean J Urol 2011;52:189. http://dx.doi.org/10.4111/kju.2011.52.3.189

23. Elshal AM, Elmansy HM, Elhilali MM. Can we predict the outcome of $532 \mathrm{~nm}$ laser photoselective vaporization of the prostate? Time to event analysis. J Urol 2012;188:1746-53. http://dx.doi.org/10.1016/i. juro.2012.07.030

24. Elshal AM, Elmansy HM, Elhilali MM. Two laser ablation techniques for a prostate less than $60 \mathrm{~mL}$ : Lessons learned 70 months after a randomized controlled trial. Urology 2013;82:416-22. http://dx.doi. org/10.1016/i.urology.2013.02.074

25. Bachmann A, Muir GH, Collins EJ, et al. 180-W XPS GreenLight laser therapy for benign prostate hyperplasia: Early safety, efficacy, and perioperative outcome after 201 procedures. Eur Urol 2012;61:600-7. http://dx.doi.org/10.1016/i.eururo.2011.11.041

26. Elmansy HM, Kotb A, Elhilali MM. Holmium laser enucleation of the prostate: Long-term durability of clinical outcomes and complication rates during 10 years of followup. J Urol 2011;186:1972. http:// dx.doi.org/10.1016/i.juro.2011.06.065
27. Elshal AM, Elkoushy MA, El-Nahas AR, et al. Greenlight laser (XPS) photoselective vapo-enucleation of the prostate versus holmium laser enucleation of the prostate for treatment of symptomatic benign prostate hyperplasia: A randomized controlled study. J Urol 2015;193:927-34. http://dx.doi.org/10.1016/i. juro.2014.09.097

28. Elmansy H, Baazeem A, Kotb A, et al. Holmium laser enucleation versus photoselective vaporization for prostatic adenoma greater than $60 \mathrm{ml}$ : Preliminary results of a prospective randomized clinical trial. J Urol 2012;188:216. http://dx.doi.org/10.1016/i.juro.2012.02.2576

29. Elkoushy MA, Elshal AM, Elhilali MM. Holmium laser transurethral incision of the prostate: Can prostate size predicts the long-term outcome? Can Urol Assoc J 2015;9:248-54. http://dx.doi.org/10.5489/ cuai. 2735

30. Elmansy HM, Elzayat E, Elhilali MM. Holmium laser ablation versus photoselective vaporization of prostate less than 60 cc: Long-term results of a randomized trial. J Urol 2010;184:2023-8. http://dx.doi. org/10.1016/i.juro.2010.06.107

31. Elkoushy MA, Elshal AM, Elhilali MM. Reoperation after holmium laser enucleation of the prostate for management of benign prostate hyperplasia: Assessment of risk factors with time to event analysis. J Endourol 2015;29:797-804. http://dx.doi.org/10.1089/end.2015.0060

32. Elmansy HM, Kotb A, Elhilali MM. Is there a way to predict stress urinary incontinence after Holmium laser enucleation of the prostate? J Urol 2011;186:1977-81. http://dx.doi.org/10.1016/i. juro.2011.06.063

33. Cornu JN, Ahyai S, Bachmann A, et al. A systematic review and meta-analysis of functional outcomes and complications following transurethral procedures for lower urinary tract symptoms resulting from benign prostatic obstruction: An update. Eur Urol 2015;67:1066-96. http://dx.doi.org/10.1016/i. eururo.2014.06.017

34. Netsch C, BachT. Vaporization vs. enucleation techniques for BPO: Do we have a standard? Curr Opin Urol 2015;25:45-52. http://dx.doi.org/10.1097/MOU.0000000000000125

Correspondence: Dr. Mostafa M. Elhilali, Professor of Urology, Royal Victoria Hospital, McGill University Health Centre, 1001 Boulevard Decarie, D05.5327, Montreal, QC, Canada H4A 3JI; mostafa.elhilali@muhc.mcgill.co 